\title{
Questionable benefits and unavoidable personal beliefs: defending conscientious objection for abortion
}

\author{
Bruce Philip Blackshaw (ㅇ, ' Daniel Rodger (1) ${ }^{2}$
}

'Philosophy, University of Birmingham, Birmingham, UK ${ }^{2}$ Allied Health Sciences, School of Health and Social Care, London South Bank University, London, UK

\section{Correspondence to} Bruce Philip Blackshaw, Philosophy, University of Birmingham, Birmingham B15 2TT, UK;

bblackshaw@gmail.com

Received 10 May 2019 Revised 7 August 2019

Accepted 15 August 2019

Published Online First

31 August 2019
Check for updates

(C) Author(s) (or their employer(s)) 2020. No commercial re-use. See rights and permissions. Published by BMJ.

To cite: Blackshaw BP, Rodger D. J Med Ethics 2020;46:178-182.

\section{ABSTRACT}

Conscientious objection in healthcare has come under heavy criticism on two grounds recently, particularly regarding abortion provision. First, critics claim conscientious objection involves a refusal to provide a legal and beneficial procedure requested by a patient, denying them access to healthcare. Second, they argue the exercise of conscientious objection is based on unverifiable personal beliefs. These characteristics, it is claimed, disqualify conscientious objection in healthcare. Here, we defend conscientious objection in the context of abortion provision. We show that abortion has a dubitable claim to be medically beneficial, is rarely clinically indicated, and that conscientious objections should be accepted in these circumstances. We also show that reliance on personal beliefs is difficult to avoid if any form of objection is to be permitted, even if it is based on criteria such as the principles and values of the profession or the scope of professional practice.

\section{INTRODUCTION}

There have been some strong criticisms of the use of conscientious objection (CO) in healthcare recently, particularly regarding abortion provision. Schuklenk and Smalling state that 'medical professionals have no moral claim in liberal democratic societies to the accommodation of their individual conscientious objections'. ${ }^{1}$ Fiala and Arthur maintain that $\mathrm{CO}$ is not a right, but rather an unethical refusal to treat and should be more accurately termed 'dishonourable disobedience'. 2 They see $\mathrm{CO}$ as 'an abandonment of professional obligations to patients'. ${ }^{2}$ Savulescu and Schuklenk claim that 'individual values ought not to govern delivery of healthcare at the bedside'. ${ }^{3}$

Two important themes have emerged in these critiques that we wish to address in the context of abortion provision. First, that $\mathrm{CO}$ involves a refusal to provide a legal and beneficial procedure requested by a patient, denying them access to healthcare. Second, that the exercise of CO for abortion provision is based on unverifiable personal beliefs, and $\mathrm{CO}$ should not be permitted on this basis.

In response, we demonstrate that in the majority of scenarios, abortion is arguably not medically beneficial, is not clinically indicated, and therefore refusal to provide abortion in these situations could be reasonably described as what Montgomery terms conscientious discretion, not CO. ${ }^{4}$ Although this might be abrogated by the scope of practice, we argue that CO should be permitted in these circumstances. We show that reliance on personal beliefs is difficult to avoid if any form of $\mathrm{CO}$ is to be permitted-objections that appeal to the principles and values of the profession as their basis are still contingent on personal beliefs.

Before we examine these claims, it is important to note that the intention of $\mathrm{CO}$ is to allow doctors (we refer to doctors throughout, but our arguments are relevant to other healthcare professionals) to refrain from being involved in certain treatments that violate their personal beliefs-not to deny services to a patient who is requesting it. If a procedure is controversial and consequently a majority of practitioners object to performing it, it is possible that these services may be more difficult to access. Obtaining services may even delayed, perhaps-in rare cases-beyond the point where they are legally obtainable, but this is not the goal of CO.

We also sympathise with some of the criticism levelled at CO: clearly, if any legal and beneficial treatment can be opted out of on the basis of an appeal to conscience, this could be significantly detrimental to patient care. Additionally, as Savulescu points out, ${ }^{5}$ there are some beliefs that should not be permitted to be used as the grounds for $\mathrm{CO}$, such as discriminatory or bigoted beliefs regarding which patients should be treated. We are not defending $\mathrm{CO}$ in general here, but $\mathrm{CO}$ in a specific scenario: abortion provision.

\section{IS ABORTION BENEFICIAL?}

Critics of CO to abortion emphasise that it involves the denial of a beneficial medical procedure that women are legally entitled to receive. Fiala and Arthur state that if the treatment is legal, within the HCP's qualifications, requested by a mentally healthy patient, and primarily beneficial (which abortion is), there is simply no excuse to refuse'. Giubilini believes patients should receive 'the legal and beneficial medical treatment they request or that is in their best interest'. ${ }^{6}$ Savulescu similarly refers to 'medical interventions that are legal, beneficial, desired by the patient'.

These writers assume or claim that abortion is a beneficial medical procedure, but provide no evidence that this is so, warranting examination. Additionally, in the case of pregnancy, it is important to distinguish between 'beneficial' and 'clinically indicated'. That an abortion might have socioeconomic benefits or minor health benefits does not entail it is clinically indicated: if this were so, abortion would be clinically indicated for all pregnancies, which is absurd. In our view, pregnancy would need to pose a substantially elevated 
risk above the normal risks of pregnancy to be clinically indicated. In the UK, this is rare: the statutory grounds for abortions are recorded on Form HSA1, which lists five categories, and in 2018, there were 145 abortions out of 200608 performed in England and Wales on 'Ground A' and 'Ground B'. 7 These are based on risk to the pregnant woman's life, and prevention of grave permanent injury.

\section{ABORTION CATEGORIES}

Requests for abortion can be usefully divided into four categories (suggested by an anonymous reviewer): (1) pregnancies that pose a threat to the life of the mother; (2) pregnancies involving severe fetal deformities; (3) pregnancies resulting from rape or incest; (4) low-risk healthy pregnancies, often termed 'social abortions'. Abortions in the first category are generally uncontroversial and are both medically beneficial and clinically indicated because they are necessary to preserve the woman's life. Mental health grounds are often used to justify abortions in other categories. It is by no means clear, however, that abortion positively impacts mental health or that denial of abortion has a long-term negative impact. Numerous studies have indicated that induced abortion may actually be harmful to mental health, ${ }^{8-12}$ while others have suggested abortion has little or no impact. ${ }^{13}$ Importantly, though, as Fergusson et al state, there is no clear evidence that abortion reduces mental health risks. ${ }^{9}$

It might be objected that in cases of severe fetal deformities and pregnancy resulting from rape or incest, abortion is more likely to positively impact mental health. Steinberg's review found that women who have later abortions for fetal anomaly have similar mental health outcomes to those who give birth to children with severe mental or physical conditions. ${ }^{14}$ We are unaware of studies comparing the mental health outcomes of the victims of rape. Currently, there is no firm evidence abortion contributes positively to mental health in these scenarios, and so it is doubtful that abortion is clinically indicated.

The final category-'social abortions'-are not clinically indicated by definition. In the UK, over $97 \%$ of abortions are recorded as being carried out under 'Ground C', which requires that 'the continuance of the pregnancy would involve risk, greater than if the pregnancy were terminated, of injury to the physical or mental health of the pregnant woman'. ${ }^{15}$ About 99.9\% of these are recorded as being on the grounds of risk to mental health. ${ }^{7}$ Given there is no clear evidence that abortion reduces mental health risks, it seems likely that these abortions fall into the 'social' category. Indeed, surveys of women seeking abortions confirm this: Chae et al identified that the most frequently reported motivations for seeking an abortion were socioeconomic concerns or a desire to limit childbearinghealth concerns were not an important motivating factor. ${ }^{16}$ We conclude that abortion is of no clear medical benefit with regard to mental health, and that in the vast majority of cases, patients are not seeking abortions for health reasons.

One possible objection, however, is to claim that abortion carries significantly less risk to a woman's physical health than pregnancy and childbirth. For example, Raymond and Grimes report that mortality rates for childbirth are 14 times higher than induced abortion. ${ }^{17}$ However, Calhoun responds by arguing that this claim is 'unsupported by the literature and there is no credible scientific basis to support it'. ${ }^{18} \mathrm{He}$ identifies a number of methodological factors that make measuring maternal mortality difficult: for example, deaths attributable to abortion are often only recorded as resulting from the immediate cause of death rather than abortion. To further complicate matters, a recent systematic review showed that different pregnancy outcomesmiscarriage, induced abortion and childbirth-were associated with significant differences in long-term mortality rates. ${ }^{19}$ When compared with childbirth, induced abortion was correlated with an elevated mortality rate for several years, even when controlling for psychological factors and economic status. Induced abortion was shown to reduce overall life expectancy, while childbirth had a positive effect, although the causal mechanisms remain unclear. It seems fair to say that currently, there is no conclusive evidence that an induced abortion carries a significantly lower risk than completing a pregnancy, ceteris paribus.

\section{PROFESSIONAL DISCRETION}

That the overwhelming majority of abortions arguably provide no significant medical benefit, are not clinically indicated and are not requested for health reasons is of considerable import in this debate. Montgomery notes that English law 'has consistently rejected the idea that healthcare law is a matter of consumer rights, in which patients demand and receive the service that they want'. ${ }^{4}$ Clinicians have broad conscientious discretion to decide what will provide the most clinical benefit for their patients. Indeed, in the UK, the General Medical Council advises that 'the law does not require doctors to provide treatments or procedures that they have assessed as not being clinically appropriate or not of overall benefit to the patient'. ${ }^{20}$ This suggests that, if, in their clinical judgement, an abortion offers negligible medical benefit to a patient, doctors are prima facie entitled to decline to provide one. This is what Sulmasy refers to as 'professional discretionary space', ${ }^{21}$ which is necessary for the practice of good medicine. In Montgomery's view, professional discretion is respected in healthcare law because of the belief that it provides 'a reliable protection for patient interests'. ${ }^{4} \mathrm{He}$ notes that the UK's 1967 Abortion Act is explicitly framed to enshrine professional discretion by referring to evaluation of risk of injury to physical or mental health as a determining factor.

Returning to the claim that $\mathrm{CO}$ to abortion involves the denial of a beneficial medical procedure, it is clear that in the majority of cases this is arguably not the case, and this severely undermines arguments against CO predicated on this claim. In fact, if a procedure is not beneficial, then given the broad conscientious discretion that Montgomery discusses, conscientiously objecting to abortion provision is strictly unnecessary in most cases-based on the available evidence, a doctor could reasonably conclude in most cases that abortion is not clinically indicated and exercise their professional discretion to decline the procedure.

How might opponents of CO respond? In a subsequent paper, Savulescu, writing with Schuklenk, adds the additional claim that doctors are obliged to conform to their 'scope of professional practice'. ${ }^{3}$ They consider that this scope of practice-which they consider is ultimately determined by society-includes abortion provision. Again, Savulescu and Schuklenk implicitly assume abortion is beneficial, and so they focus on the claim that doctors should not be able to conscientiously object to requests for abortion that are legal and within the scope of practice. Obviously, their argument is weakened if abortion is not beneficial in the majority of cases, as we have argued. However, it raises the question, if abortion is not obviously medically beneficial, not clinically indicated, but is desired by the patient and is within the scope of professional practice, should doctors' professional discretion be over-ridden and they be obliged to provide an abortion if it is requested? Savulescu and Schuklenk could argue that since the profession has clearly accepted abortion provision as 
part of professional practice, then a decision regarding professional discretion has already been made.

Perhaps this has some validity, but their argument is regarding conscientious objection, not discretion. While the scope of professional practice provides a prima facie reason to request doctors to supply abortions when sought by patients, there seems no compelling reason to force doctors to do so if they strongly object on conscience grounds, and the abortion is not clinically indicated. To do so would mean privileging patient autonomy over the moral integrity of doctors, which seems unjustified when alternatives are available. In Toni Saad's words, 'if a procedure does not conform to the goals of medicine, then it is unclear that it is a medical practitioner's duty to do it'..22 According to Saad, the goals of medicine are the 'restoration and maintenance of health'. Savulescu similarly states that the 'primary goal of a health service is to protect the health of its recipients'.

\section{PERSONAL BELIEFS AND VALUES}

Let us now consider criticism that $\mathrm{CO}$ is based on individuals' personal beliefs and values. In Savulescu's view, if clinicians are unwilling to provide care because of a conflict with their personal values, 'they should not be doctors'. ${ }^{5}$ His primary concern is that patients obtain the care they need, and he believes $\mathrm{CO}$ potentially disrupts this. However, Savulescu is also concerned with the content of personal beliefs, claiming $\mathrm{CO}$ opens a path to 'idiosyncratic, bigoted, discriminatory medicine', whether beliefs are secular or religious. ${ }^{5}$ Fiala and Arthur are also troubled by CO's reliance on personal beliefs, referring to them as 'non-verifiable' and 'subjective'. '2 Schuklenk and Smalling similarly criticise 'untestable' and 'arbitrary' conscience claims. ${ }^{1}$

Of course, all COs by definition are based on personal moral convictions held by the objector, and so they are correct: these beliefs are untestable. Our moral beliefs, whether predominantly religious or secular, may be informed by scientific evidence but science cannot tell us what is moral and what is not. Embryology, for example, can tell us when the human zygote is formed in the fertilisation process and when a fetus is capable of consciousness, but it cannot tell us whether it is morally permissible to end its life prematurely via abortion. Does this lack of testability disqualify CO from being used in medicine? Fiala and Arthur instead suggest that the widely cited bioethical principles of beneficence and non-maleficence be used to adjudicate objections as they 'are not due to an individual doctor's subjective personal or religious beliefs'. ${ }^{2}$ These principles are, however, equally untestable ethical standards, despite broad agreement on their importance. They are derived from a range of moral theories which cannot be empirically verified. This implies that a lack of testability is not a sustainable criticism of conscience claims.

It seems, then, that critics' primary complaint is that the beliefs used to ground objections are personal beliefs. One concern is that personal beliefs can vary widely between individuals. Giubilini describes the character of conscience as formal, not substantive: an 'empty box that can be filled with various substantial moral views'. ${ }^{6}$ This, he believes, implies the content of conscience cannot be used to defend $\mathrm{CO}$-because of moral diversity, this would entail treating all COs equally. In healthcare, this can obviously be problematic: Savulescu and Schuklenk provide an example of a doctor who believes that the very elderly should not receive life prolonging medical treatment. ${ }^{3}$

Almost all of these ethicists do concede, however, that there are circumstances when doctors should be able to object. For example, Savulescu and Schuklenk state that 'we do want doctors to act on their conscience when the stakes are high, and their conscience is right', citing the example of a US Navy nurse who objected to the force feeding of Guantanamo detainees as torture. $^{3}$ Schuklenk and Smalling also refer to torture, as do Fiala and Arthur, who also imply that non-therapeutic infant male circumcision is objectionable. ${ }^{2}$ Their difficulty is justifying these exceptions while maintaining the stance that $\mathrm{CO}$ based on personal beliefs should not be permitted. In particular, as they all maintain that abortion should be provided on patient request, their criteria must be able to rule out objections to abortion provision.

One commonly cited criterion is that treatments must be legal, which generally rules out torture. This is not, however, sufficient to rule all cases where it is agreed objecting is desirableapparently Savulescu and Schuklenk's example of force-feeding patients was legal. Another example is the symphysiotomy, a delivery procedure practised until the 1980s in Ireland, which Savulescu and Schuklenk describe as barbaric. (It is worth noting that in some modern contexts a symphysiotomy is still considered a lifesaving procedure..$^{23}$ ) Presumably they would have objected to being directed to provide such a procedure at the time, given Caesarean sections were available and had far fewer side effects. Another example is non-therapeutic infant male circumcision, which is also legal. A growing number of medical ethicists argue that children, regardless of sex, should not have parts of their sexual organs removed before they are able to understand the consequences of doing so. ${ }^{24}$

\section{VALUES AND PRINCIPLES OF MEDICINE}

As we have seen, one approach is to appeal to beneficence and non-maleficence as legitimate grounds for objecting rather than individual beliefs. Giubilini similarly believes doctors can object when they 'are asked to perform activities which conflict with the values and principles of medicine'. ${ }^{6}$ The difficulty here is that these values and principles are so broad as to be of little value in demarcating whether a certain treatment should be objected to. Doctors and ethicists may agree that they are important normative principles, but they may have differing views on what weight each principle holds in ethical decision-making-and these are personal beliefs.

Additionally, a crucial concept underlying these principles is the nature of harm, the understanding of which varies, and is itself a personal belief-a contentious one. As Kahane and Savulescu explain, harm is an ambiguous concept that is not well understood. ${ }^{25}$ They propose an account based on statistical normality: someone is harmed by actions that result in their being placed below statistical normality in some respect. Interestingly, Purshouse points out that if a painful disease is widespread in a population, then under this account suffering from that pain is statistically normal, and giving someone this disease does not harm them. ${ }^{26}$ Returning to abortion, it would seem that if it were statistically normal that women continued with their pregnancies, on Kahane and Savulescu's account, women who were denied abortions could not have been harmed.

Doctors may even share similar secular or religious beliefs regarding harm, and yet still disagree about what action is in the best interest of a patient, particularly in the areas most likely to generate objections: even if we have access to the same information, ethical decision-making is heavily influenced by our personal beliefs. One of the most widely used models of ethical decision-making is James Rest's four component model. Each component-moral awareness, moral judgment, moral motivation and moral action-depends to varying degrees on personal 
moral beliefs ${ }^{27}$, which may be shaped by our age, gender, culture, professional experience, religious beliefs and family values.

\section{SCOPE OF PROFESSIONAL PRACTICE}

A more promising alternative might be to appeal to the scope of professional practice-we noted earlier that Savulescu and Schuklenk suggest this can be employed as a constraint on COs, as do Schuklenk and Smalling. ${ }^{3}$ Because performing abortions is within some doctors' scope of professional practice, they believe they should not be permitted to object. There are, however, some issues with this approach. We have already argued that in the vast majority of cases that doctors should not be forced to perform procedures they object to on conscience grounds and that are not clinically indicated.

Additionally, in the UK, the law recognises that abortion provision is unique and controversial, and therefore explicitly allows doctors to exempt themselves except for the very few cases where a woman's life is endangered. The British Medical Association states that 'doctors should have a right to conscientiously object to participation in abortion'. ${ }^{28}$ It seems that there is widespread agreement that the scope of practice should not over-ride personal conscience in this instance.

Finally, Savulescu and Schuklenk state that the scope of professional practice should allow for no exceptions. Admittedly, if personal beliefs are to be rejected as the basis of objections, they have little choice but to rigidly enforce objective criteria of some kind, but this comes at a considerable costeven treatments believed to be harmful cannot be objected to provided they are part of the scope of practice. Rather than objecting, Savulescu and Schuklenk argue that doctors must be complicit, and instead lobby to change laws and practices that they feel are immoral.

This is a controversial position-do we really want doctors to doggedly follow the scope of professional practice, directed say, by a superior, even when they believe the consequences will be harmful or lethal for the patient? We noted earlier that Savulescu and Schuklenk describe symphysiotomies as barbaric, but they were within the scope of practice at the time, and so the implication is that doctors could not object to performing them. ${ }^{29}$ What if a practice is genuinely evil, rather than barbaric? Savulescu and Schuklenk consider this question-if doctors believe this about a practice, they claim they should not be involved in the relevant specialty, stating objecting is an 'unjustifiable compromise' for those doctors. ${ }^{3}$ This is itself a normative claim-a personal belief-and seems presumptuous: surely doctors can decide for themselves what compromises they can make when confronted with such a situation. Additionally, if the profession really is involved in an evil practice, it seems hardly conducive to good healthcare to purge all doctors who object to it.

\section{CONCLUSION}

We have explored two important objections to $\mathrm{CO}$ with respect to abortion provision. Contrary to critics of $\mathrm{CO}$ who claim it involves the denial of a legal, beneficial procedure, we have shown that abortion has a dubitable claim to be considered medically beneficial in the vast majority of cases, and is rarely clinically indicated. We argue that doctors should be able to $\mathrm{CO}$ in these circumstances. Most critics agree that some form of objection should be permitted in certain scenarios, and they attempt to distinguish CO based on unverifiable personal beliefs from objections based on criteria such as the values and principles of medicine. We have shown that these also depend on personal beliefs, particularly regarding the nature of harm, and conclude that reliance on personal beliefs is difficult to avoid and not a valid criticism of CO. The alternative criterion of the scope of professional practice is also problematic. More broadly, we suggest that if a procedure or treatment within the scope of practice is not clinically indicated, then it should qualify for CO.

Acknowledgements We are grateful to two anonymous referees for their very helpful feedback. We are also thankful to Trevor Stammers, Toni Saad and Nick Colgrove for their comments, all of which have helped significantly improve this paper.

Contributors The majority of this paper has been written by BPB, the first author. $D R$, the second author, has also contributed significantly and this paper could not have been written without him.

Funding The authors have not declared a specific grant for this research from any funding agency in the public, commercial or not-for-profit sectors.

Competing interests None declared.

Patient consent for publication Not required.

Provenance and peer review Not commissioned; externally peer reviewed.

\section{ORCID iDs}

Bruce Philip Blackshaw http://orcid.org/0000-0002-9115-582X

Daniel Rodger http://orcid.org/0000-0002-2121-7167

\section{REFERENCES}

1 Schuklenk U, Smalling R. Why medical professionals have no moral claim to conscientious objection accommodation in liberal democracies. J Med Ethics 2017:43(4):234-40.

2 Fiala C, Arthur JH. There is no defence for 'Conscientious objection' in reproductive health care. Eur J Obstet Gynecol Reprod Biol 2017;216:254-8.

3 Savulescu J, Schuklenk U. Doctors have no right to refuse medical assistance in dying, abortion or contraception. Bioethics 2017;31(3):162-70.

4 Montgomery J. Conscientious objection: personal and professional ethics in the public square. Med Law Rev 2015;23(2):200-20.

5 Savulescu J. Conscientious objection in medicine. BMJ 2006;332(7536):294-7.

6 Giubilini A. Objection to conscience: an argument against conscience Exemptions in healthcare. Bioethics 2017;31(5):400-8.

7 Department of Health and Social Care. Abortion statistics, England and Wales, 2018. Available: https://assets.publishing.service.gov.uk/government/uploads/system/ uploads/attachment_data/file/808556/Abortion_Statistics_England_and_Wales_ 2018_1_.pdf [Accessed Aug 2019].

8 Fergusson DM, Horwood LJ, Ridder EM. Abortion in young women and subsequent mental health. J Child Psychol Psychiatry 2006;47(1):16-24.

9 Fergusson DM, Horwood LJ, Boden JM. Abortion and mental health disorders: evidence from a 30-year longitudinal study. Br J Psychiatry 2008;193(6):444-51.

10 Fergusson DM, Horwood LJ, Boden JM. Reactions to abortion and subsequent mental health. Br J Psychiatry 2009;195(5):420-6.

11 Coleman PK. Abortion and mental health: quantitative synthesis and analysis of research published 1995-2009. Br J Psychiatry 2011;199(3):180-6.

12 Jacob L, Kostev K, Gerhard C, et al. Relationship between induced abortion and the incidence of depression, anxiety disorder, adjustment disorder, and somatoform disorder in Germany. J Psychiatr Res 2019:114:75-9.

13 Steinberg JR, Laursen TM, Adler NE, et al. Examining the association of antidepressant prescriptions with first abortion and first childbirth. JAMA Psychiatry 2018;75(8):828-34.

14 Steinberg JR. Later abortions and mental health: psychological experiences of women having later abortions--a critical review of research. Womens Health Issues 2011;21(3 Suppl):S44-S48.

15 UK Government. The National archives. abortion act 1967. London: HM Stationery office 1967. Available: https://www.legislation.gov.uk/ukpga/1967/87/contents [Accessed Aug 2019].

16 Chae S, Desai S, Crowell M, et al. Reasons why women have induced abortions: a synthesis of findings from 14 countries. Contraception 2017:96(4):233-41.

17 Raymond EG, Grimes DA. The comparative safety of legal induced abortion and childbirth in the United States. Obstet Gynecol 2012;119(2 Pt 1):215-9.

18 Calhoun B. The maternal mortality myth in the context of legalized abortion. Linacre $Q$ 2013;80(3):264-76.

19 Reardon DC, Thorp JM. Pregnancy associated death in record linkage studies relative to delivery, termination of pregnancy, and natural losses: a systematic review with a narrative synthesis and meta-analysis. SAGE Open Med 2017;5.

20 General Medical Council. Personal beliefs and medical practice, 2013. Available: https://www.gmc-uk.org/-/media/documents/personal-beliefs-and-medical-practice_ pdf-58833376.pdf [Accessed Aug 2019]. 


\section{Original research}

21 Sulmasy DP, Tolerance SDP. Tolerance, professional judgment, and the discretionary space of the physician. Camb Q Healthc Ethics 2017;26(1):18-31.

22 Saad TC. Mistakes and missed opportunities regarding cosmetic surgery and conscientious objection. J Med Ethics 2018;44(9):649-50.

23 Wykes CB, Johnston TA, Paterson-Brown $S$, et al. Symphysiotomy: a lifesaving procedure. BJOG 2003;110(2):219-21.

24 Earp BD. Boys and girls alike: The ethics of male and female circumcision. In: Gathman ECH, ed. Women, Health, \& Healthcare: Readings on Social, Structural, \& Systemic Issues. Dubuque, lowa: Kendall Hunt Publishing Company, 2016: 113-6.

25 Kahane G, Savulescu J. The concept of harm and the significance of normality. J Appl Philos 2012;29(4):318-32.
26 Purshouse C. A defence of the counterfactual account of harm. Bioethics 2016;30(4):251-9.

27 Rest J. Background: Theory and research. In: Rest J, Narvaez D, eds. Moral development in the professions: Psychology and applied ethics. New Jersey: Lawrence Erlbaum Associates Inc, 1994: 1-26.

28 British Medical Association. Expression of doctors' beliefs, 2018. Available: https:// www.bma.org.uk/advice/employment/ethics/expressions-of-doctors-beliefs [Accessed Apr 2019]

29 Gamble NK, Pruski M, Acts M. Medical acts and conscientious objection: what can a physician be Compelled to do? New Bioeth 2019:1-21. 